WILEY-VCH

\title{
Polyurethanes from Direct Organocatalytic Copolymerization of p-Tosyl Isocyanate with Epoxides
}

\author{
Mingchen Jia, Nikos Hadjichristidis, Yves Gnanou, ${ }^{*}$ and Xiaoshuang Feng*
}

\author{
Dr. M. Jia, Prof. Dr. N. Hadjichristidis, Prof. Dr. Y. Gnanou, and Dr. X. Feng \\ Physical Sciences and Engineering Division and KAUST Catalysis Center \\ King Abdullah University of Science and Technology (KAUST) \\ Thuwal 23955, Saudi Arabia \\ E-mail: yves.gnanou@kaust.edu.sa; xiaoshuang.feng@kaust.edu.sa \\ Supporting information for this article is given via a link at the end of the document
}

\begin{abstract}
The direct copolymerization of $p$-tosyl isocyanate (TSI) with epoxides, initiated by onium salts in the presence of trialkylborane, to produce polyurethanes is reported. The rate of copolymerization and the (regio)selectivity were investigated in relation to the trialkylborane and initiator used. Under optimized conditions such copolymerizations have been successfully performed for a wide range of epoxides, including ethylene oxide, propylene oxide, 1-octene oxide, cyclohexene oxide, and allyl glycidyl ether. These copolymerizations afford a new category of polyurethanes, clear of side products such as cyclic oxazolidinone, isocyanurate, and poly(isocyanate) linkages. The experimental conditions used in this work are compatible with those for the organocatalytic (co)polymerization of other oxygenated monomers and $\mathrm{CO}_{2}$, holding the potential for their terpolymerization with $p$-tosyl isocyanate and the development of new materials with unprecedented properties.
\end{abstract}

Polyurethanes are important industrial polymers that are widely used in our daily life, from soft foams and bed mattresses to rigid foams for thermal insulation, paints, coatings, construction, elastomers, and adhesives. ${ }^{[1]}$ Traditionally, polyurethanes are produced by step-growth polycondensation reaction between diisocyanates and di- or multifunctional alcohols. ${ }^{[2]}$ Barring the example of isocyanates, polyurethanes with pendent hydroxyl groups can also be prepared by polycondensation of bifunctional five-membered cyclic carbonates with diamines. ${ }^{[3]}$ The ringopening polymerization (ROP) of cyclic urethanes represents another important alternative route to polyurethane synthesis. Höcker and coworkers first reported the cationic ROP of 6membered and 7-membered cyclic urethanes. ${ }^{[4]}$ Under anionic polymerization conditions, 6 -membered ${ }^{[5]}$ and 5-membered cyclic urethanes $^{\left[{ }^{[]}\right.}$also lead by ROP to the corresponding polyurethanes. In addition to the above strategies, the direct copolymerization of aziridines with $\mathrm{CO}_{2}$ reported by lkariya et al. also produce polymers with urethane linkages, albeit not alternating; ${ }^{[7]}$ finally polycondensation of $\mathrm{CO}_{2}$, diamines and dihalides in the presence of $\mathrm{Cs}_{2} \mathrm{CO}_{3}$ also yield polyurethanes with some carbonate linkages. ${ }^{[8]}$

Our group has been focused on the synthesis of "oxygenated" polymers using borate complexes as initiators. Since the first report in 2016 on the triethylborane (TEB)-mediated copolymerizations of epoxides with $\mathrm{CO}_{2},{ }^{[9]}$ the use of trialkylborane (TAB) associated with growing anions in ringopening homopolymerization or copolymerization has received widespread attention. As a metal-free method, TAB-mediated polymerizations can be used for the synthesis of a wide range of (co)polymers with complex architecture of low-to-high molar mass and applied to a wide range of monomers. ${ }^{[10]}$ Up to now, TAB has been successful applied to the anionic copolymerization of epoxides with $\mathrm{CO}_{2},{ }^{[9,11]}$ with anhydrides, ${ }^{[12]}$ with carbonyl sulfide $(\mathrm{COS})^{[13]}$ as well as to epoxide homopolymerization ${ }^{[14]}$ (Scheme 1A). The fact that isocyanates, along with $\mathrm{CO}_{2}$ and $\mathrm{COS}$, can be categorized as heteroallenes prompted us to investigate their copolymerization with epoxides in a similar way (Scheme 1B). In addition to producing polyurethane directly by a different synthetic strategy, a new option is made available to generate polymers exhibiting unique thermal and mechanical properties after incorporation of polyurethane blocks or segments.

Because isocyanates are more active than $\mathrm{CO}_{2}$, its copolymerization with epoxides is challenging. Isocyanates themselves undergo both homopolymerization and trimerization/cyclization under basic conditions; ${ }^{[15]}$ besides, they can easily generate cyclic urethanes by reaction with epoxides through [2+3] cycloaddition. ${ }^{[16]}$ During the manuscript preparation, Adriaenssens and coworkers reported the copolymerization of cyclohexene oxide with isocyanates, catalyzed by a dimagnesium complex. ${ }^{[17]}$ To avoid the formation of isocyanurates and oxazolidinones, a slow addition of isocyanate into the reaction medium was necessary.

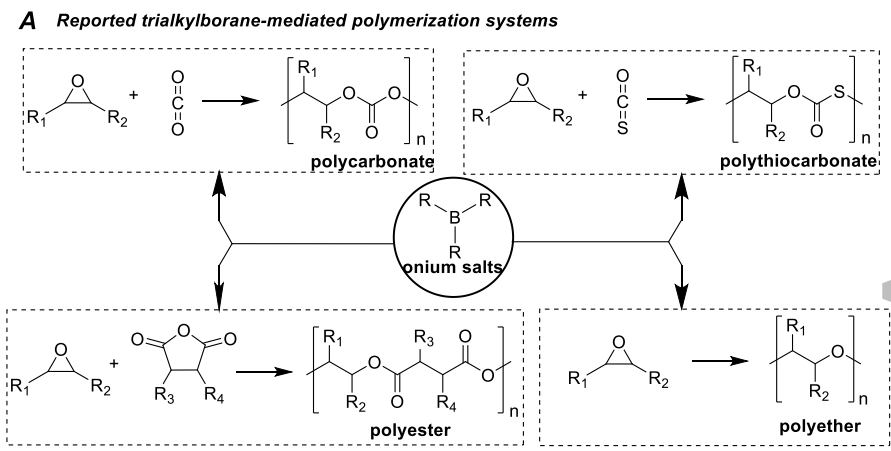

B This work: copolymerization of epoxide with p-toluenesulfonyl isocyanate

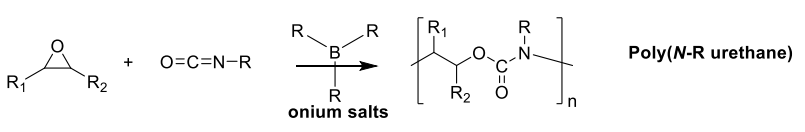

Scheme 1. Trialkylborane-mediated polymerization route to oxygenated polymers 
Table 1. Data for the Copolymerization of Isocyanate with Epoxide ${ }^{[a]}$

\begin{tabular}{|c|c|c|c|c|c|c|c|c|c|c|c|c|}
\hline Entry & $\begin{array}{l}\text { Epoxide } \\
\text { (E) }\end{array}$ & $\begin{array}{l}\text { Initiator } \\
\text { (I) }\end{array}$ & $\begin{array}{c}\text { Borane } \\
\text { (B) }\end{array}$ & $\begin{array}{l}\text { Isocyanate } \\
\text { (Ic) }\end{array}$ & $\begin{array}{c}\mathrm{E} / \mathrm{lc} / \mathrm{B} / \mathrm{l} \\
\text { (molar ratio) }\end{array}$ & $\begin{array}{c}\text { Linear } \\
\text { selectivity }^{[\mathrm{b}]} \\
(\%)\end{array}$ & $\begin{array}{c}\text { Urethane } \\
\text { selectivity[c] } \\
\text { (\%) }\end{array}$ & $\begin{array}{c}\text { Ether } \\
\text { Content }{ }^{[c]} \\
(\%)\end{array}$ & $\begin{array}{c}\left.\text { Yield }^{[d]}\right] \\
(\%)\end{array}$ & $\begin{array}{l}M_{\mathrm{n} \text { (theo })^{[\mathrm{e}]}} \\
(\mathrm{kg} / \mathrm{mol})\end{array}$ & $\begin{array}{c}M_{\mathrm{n}^{[f]}} \\
(\mathrm{kg} / \mathrm{mol})\end{array}$ & $\theta^{[f]}$ \\
\hline 1 & $\mathrm{PO}$ & PPNCl & TEB & $\mathrm{HI}$ & $5000 / 2000 / 2 / 1$ & - & 0 & 100 & - & - & $n d^{[i]}$ & nd \\
\hline 2 & $\mathrm{PO}$ & PPNCl & TEB & Al & $500 / 50 / 2 / 1$ & - & 0 & 100 & - & - & nd & nd \\
\hline 3 & PO & TBACl & TEB & TSI & $100 / 110 / 2 / 1$ & $>99$ & $>99$ & $<1$ & $>99$ & 26 & 20 & 1.13 \\
\hline 4 & $\mathrm{PO}$ & TBACI & TEB & TSI & $25 / 37.5 / 2 / 1$ & $>99$ & $>99$ & $<1$ & $>99$ & 6.4 & 5.6 & 1.12 \\
\hline 6 & $\mathrm{PO}$ & TBACI & - & TSI & $100 / 110 / 0 / 1$ & 92 & 51 & $<1$ & 34 & 8.7 & 7.0 & 1.12 \\
\hline 7 & $\mathrm{PO}$ & TBACI & TEB & TSI & $500 / 550 / 2 / 1$ & $>99$ & 73 & $<1$ & 31 & 40 & 33 & 1.15 \\
\hline $8^{[9]}$ & $\mathrm{PO}$ & TBACI & TEB & TSI & $500 / 550 / 2 / 1$ & 94 & 80 & $<1$ & 95 & 121 & 104 & 1.35 \\
\hline 9 & $\mathrm{PO}$ & TBACI & TEB & TSI & $500 / 550 / 4 / 1$ & $>99$ & 90 & $<1$ & 41 & 52 & 45 & 1.16 \\
\hline 10 & $\mathrm{PO}$ & PPNCl & TEB & TSI & $100 / 110 / 2 / 1$ & $>99$ & $>99$ & 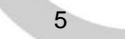 & $>99$ & 26 & 17 & 1.11 \\
\hline 11 & $\mathrm{PO}$ & PPNCl & TEB & TSI & $100 / 150 / 2 / 1$ & $>99$ & $>99$ & $<1$ & $>99$ & 26 & 19 & 1.12 \\
\hline $13^{[\mathrm{h}]}$ & $\mathrm{PO}$ & TBACI & TPB & TSI & $100 / 110 / 2 / 1$ & $>99$ & $>99$ & $<1$ & 75 & 19 & 15 & 1.19 \\
\hline $14^{[\mathrm{h}]}$ & $\mathrm{PO}$ & PPNCl & TPB & TSI & $1000 / 1100 / 0.5 / 1$ & $>99$ & $>99$ & $<1$ & $>99$ & 255 & 225 & 1.51 \\
\hline 15 & $\mathrm{PO}$ & TBACI & TsBB & TSI & $100 / 110 / 2 / 1$ & 91 & 53 & $<1$ & 27 & 6.9 & 6.2 & 1.12 \\
\hline $16^{[\mathrm{h}]}$ & EO & TBACI & TEB & TSI & $100 / 110 / 2 / 1$ & $>99$ & $>99$ & $<1$ & $>99$ & 24 & nd & nd \\
\hline 17 & $\mathrm{OO}$ & TBACI & TEB & TSI & $100 / 110 / 2 / 1$ & $>99$ & 92 & $<1$ & $>99$ & 33 & 18 & 1.13 \\
\hline 18 & AGE & TBACI & TEB & TSI & $100 / 110 / 2 / 1$ & $>99$ & $>99$ & $<1$ & $>99$ & 31 & 22 & 1.31 \\
\hline 19 & $\mathrm{CHO}$ & $\mathrm{PPNCl}$ & TEB & TSI & $100 / 110 / 2 / 1$ & $>99$ & 21 & $<1$ & 54 & 16 & 9.3 & 1.21 \\
\hline 20 & $\mathrm{PO}$ & PPNCl & TEB & TSI & $1000 / 260 / 2 / 1$ & $>99$ & $>99$ & 70 & 95 & $102^{[j]}$ & 83 & 1.26 \\
\hline
\end{tabular}

[a] The reactions were run at $25^{\circ} \mathrm{C}$ for 12 hours using THF as solvent unless otherwise noted. [b] Determined from the FTIR spectra for the crude product. [c] Determined from ${ }^{1} \mathrm{H}$ NMR spectra of the purified polymer. [d] Yield $=$ weight of the polymer obtained/theoretical polymer weight at full conversion $\times 100 \%$. [e] Theoretical molar mass $=(58.1+197.2) \times(E / I) \times y i e l d$. [ $\mathrm{f}$ ] Determined by SEC at $35^{\circ} \mathrm{C}$ using THF as the solvent and polystyrene standard. [ $\mathrm{g}$ ] The reaction was conducted at $60{ }^{\circ} \mathrm{C}[\mathrm{h}]$ The polymerization proceeded explosively. [i] nd: not detected. [j] Calculated using the equation: $M_{\mathrm{n} \text { (theo) }=}$ $(58.1+197.2) \times 260+58.1 \times 260 \times 0.7 /(1-0.7)$, where 0.7 is the mol \% content of ether from ${ }^{1} \mathrm{H}$ NMR.

A

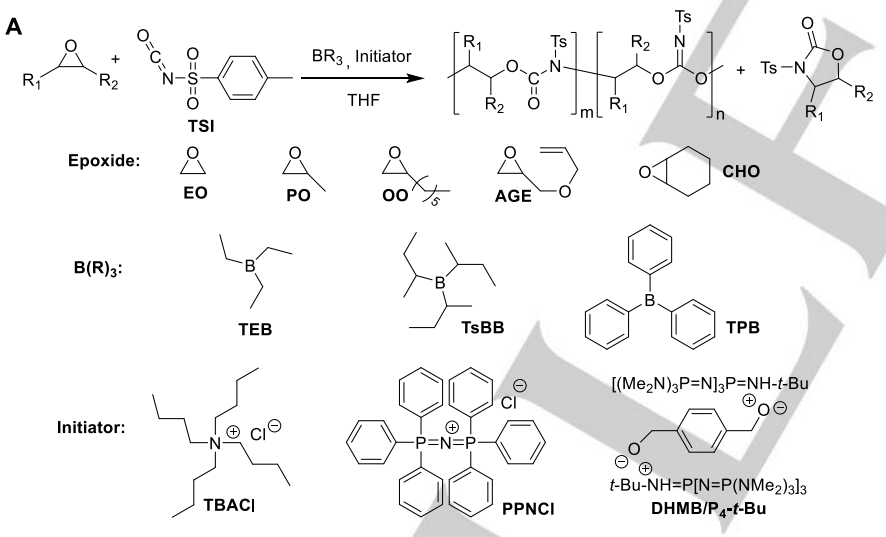

B

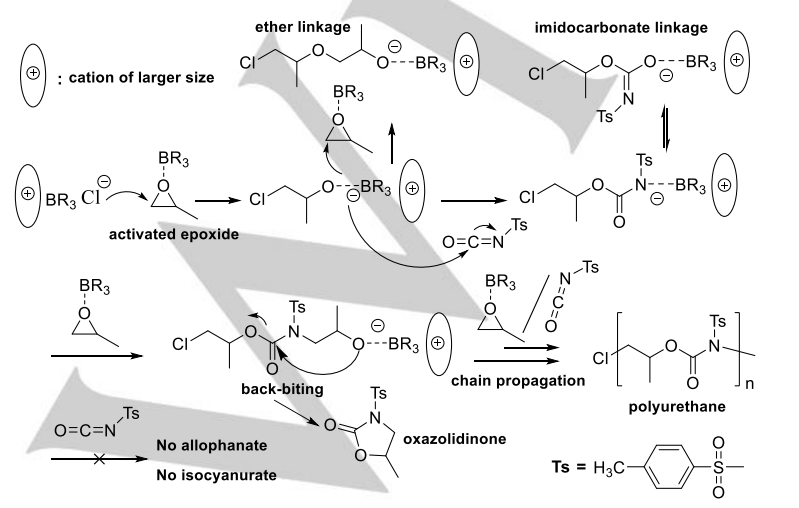

Scheme 2. (A) Trialkylborane-mediated copolymerization of $p$-tosyl isocyanate with epoxides and $(B)$ possible reaction pathways.
Our first attempt was to copolymerize isocyanates with propylene oxide under conditions typically employed in the copolymerization of $\mathrm{CO}_{2}$ with epoxide (2 eq. TEB to $\mathrm{PPNCl}$ at room temperature), hexyl isocyanate $(\mathrm{HI})$ being the first isocyanate tried. Hexyl isocyanurate, the trimer of $\mathrm{HI}$, along with polyethers were eventually produced with no incorporation of any isocyanate in the latter polymer; the cyclotrimerization of isocyanate could not be avoided despite the presence of a significant excess of $\mathrm{PO}$ and a slow addition of isocyanate (Entry 1, Table 1). This result indicates that the reactivity of $\mathrm{HI}$ is not only much higher than that of epoxide but also than that of $\mathrm{CO}_{2}$ under similar reaction conditions. The cyclotrimerization of $\mathrm{HI}$ occurs even though the growing active species is not a regular anion but a borate complex of much lower nucleophilic character. In order to undergo copolymerization with epoxides, the isocyanate chosen should therefore exhibits a reactivity comparable to or slightly higher than that of $\mathrm{CO}_{2}$. To prevent the tendency of alkyl isocyanate to undergo homopolymerization or trimerization/cyclization, we first considered steric hindrance as a means to control the reactivity of isocyanate. Adamantyl isocyanate (Al) was thus tested; however, only PPO was produced without any incorporation of isocyanate, and no formation of isocyanurate was detected (Entry 2). In a second step, we considered the electronic effects as a means to control the reactivity of isocyanates and favor their copolymerization with epoxides. Among commercially available isocyanates, $p$-tosyl isocyanate (TSI) bearing a strong electronwithdrawing group was selected for the copolymerization with 

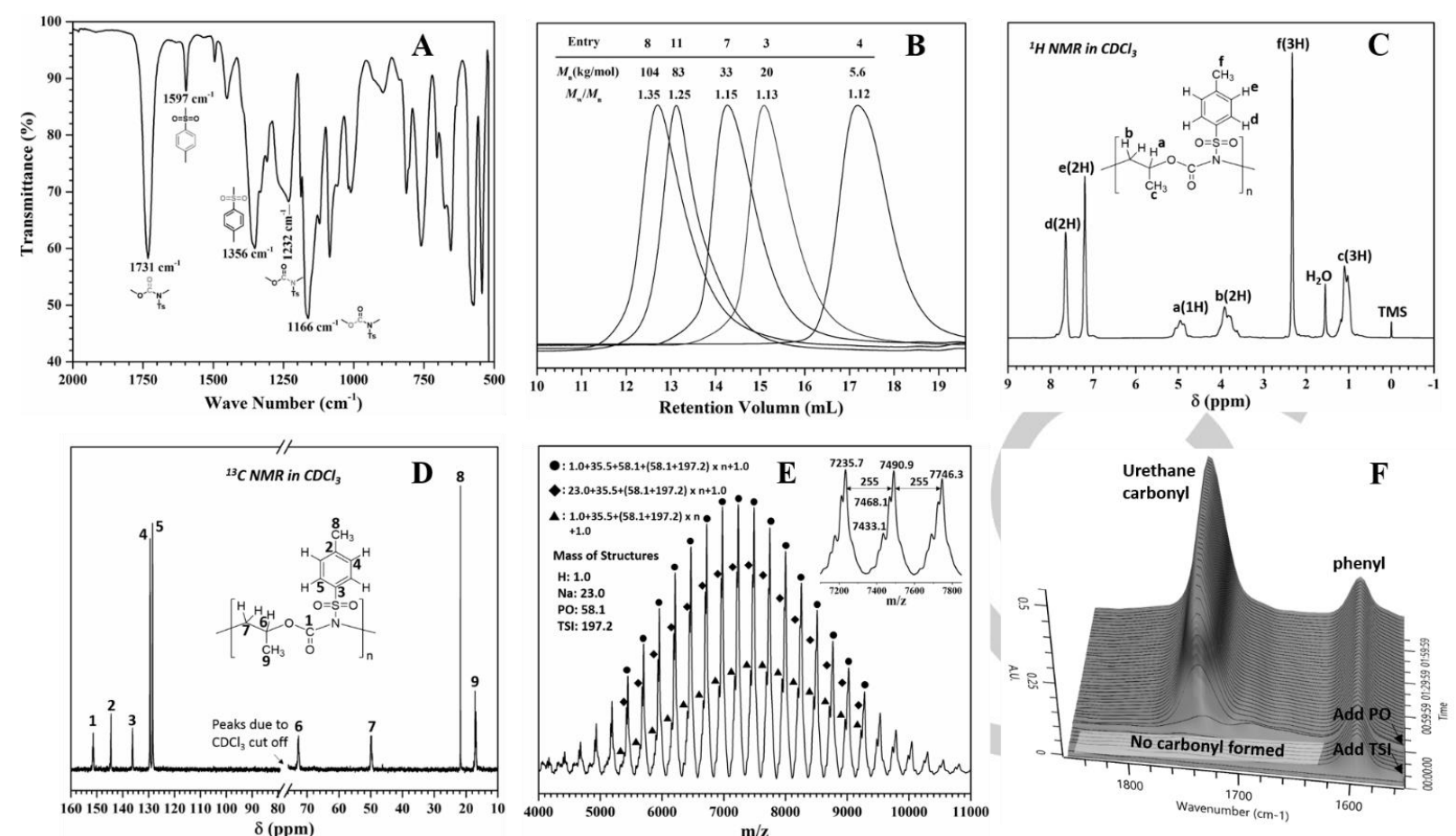

Figure 1. Characterizations of the copolymer of PO and TSI (entry 3 in Table 1): (A) FTIR spectrum of the copolymer powder; (B) SEC traces of copolymers with various molar masses using THF as the eluent and PS standards; $(\mathrm{C}){ }^{1} \mathrm{H}$ NMR of the copolymer in $\mathrm{CDCl}_{3}$; (D) ${ }^{13} \mathrm{C} \mathrm{NMR}$ of the copolymer in $\mathrm{CDCl}{ }_{3}$; $(\mathrm{E})$ MALDI-TOF spectrum for the copolymer of PO and TSI (entry 4 in Table 1) and (F) In-situ FTIR surface image in the range of $1560-1860 \mathrm{~cm}^{-1}$ for a model copolymerization of $\mathrm{PO}$ and TSI before and after addition of $\mathrm{PO}$.

epoxides (Scheme 2A). TSI is highly electrophilic, ${ }^{[18]}$ and the generated negative charge upon attack by nucleophiles can be delocalized due to the presence of the toluene sulfonyl group, giving rise to anionic species of low nucleophilic character. We reasoned that this might prevent the homopolymerization of TSI. In the presence of TEB and using TBACl as the initiator, the copolymerization of TSI with PO did occur (Entry 3).

After quenching the reaction with methanol and $\mathrm{HCl}$, the crude product was collected for FTIR characterization. A strong peak at $1731 \mathrm{~cm}^{-1}$ due to carbonyl stretching was observed. Knowing that the absorption peak for the carbonyl stretching appears at around1714 $\mathrm{cm}^{-1}$ for isocyanurates ${ }^{[19]}$ and $1783 \mathrm{~cm}^{-1}$ for oxazolidinones, ${ }^{[20]}$ the absorption at $1731 \mathrm{~cm}^{-1}$ is assumed to be due to the urethane linkages in the polymer formed. Apart from this peak, the FTIR spectrum of the precipitated product in methanol exhibited peaks at $1232 \mathrm{~cm}^{-1}$ and $1166 \mathrm{~cm}^{-1}$ corresponding to $\mathrm{C}-\mathrm{N}$ and $\mathrm{C}-\mathrm{O}$ stretchings, respectively, further confirming the presence of the urethane linkages (Figure 1A). Besides, the absorption at $1597 \mathrm{~cm}^{-1}$, together with that at 1356 $\mathrm{cm}^{-1}$ indicates the presence of tosyl groups. The SEC traces of the polymer formed showed a narrow monomodal chromatogram with a molar mass of $20 \mathrm{~kg} / \mathrm{mol}$, corroborating the formation of copolymers from TSI and PO (Figure 1B). The chemical structures of the copolymer was investigated further by NMR. In the ${ }^{1} \mathrm{H}$ NMR spectra (Figure $1 \mathrm{C}$ ) of the copolymer, we can clearly see the signals corresponding to the methylene and methine protons of PO moving to low field at $3.91 \mathrm{ppm}$ and $4.94 \mathrm{ppm}$ after formation of urethane linkages; the signals at $2.32 \mathrm{ppm}, 7.19 \mathrm{ppm}$ and 7.64 confirm the presence of TSI moieties. The fact that the molar ratio of TSI to $\mathrm{PO}$ in the copolymer formed is equal to $1: 1$ and no ether linkage signals ( 3.35 and $\sim 3.47 \mathrm{ppm})$ were observed indicate its alternating structure with absence of allophanate linkages as observed by Adriaenssens et al. in their work. ${ }^{[17]}$ The alternating structure of polyurethane was also confirmed by ${ }^{13} \mathrm{C}$ NMR (Figure 1D). The signal of the carbonyl carbon appears at $151.4 \mathrm{ppm}$, similar to that $(151.6 \mathrm{ppm})^{[21]}$ in 5methyl-3-tosyl-1,3-oxazolidin-2-one, the cyclic counterpart of poly( $N$-tosyl propylene urethane). The signals corresponding to the tertiary carbon and methylene carbon of the PO moiety appeared at $72.7 \mathrm{ppm}$ and $49.8 \mathrm{ppm}$, respectively; for comparison, the values for an alternating poly(propylene carbonate) are 72.2 ppm and 69.0 ppm. ${ }^{[22]}$ The chemical shift toward high field results from the asymmetry of urethane linkages and the position of the methylene carbon, which is adjacent to the nitrogen.

In order to identify the nature of the terminal functional group, a low-molar-mass $(5.6 \mathrm{~kg} / \mathrm{mol})$ poly( $N$-tosyl propylene urethane) sample was prepared by copolymerizing TSI and PO with a targeted DP of 25 (Entry 4). From the sample obtained, initiated by chloride, the alternating nature of the polyurethane formed could be determined by MAIDI-TOF mass spectrometry. As shown in Figure 1E, three populations corresponding two different chain ends (one with one more PO unit) and two types of ionization peaks can be observed, one is ionized by a proton $(+1.0)$ and the other by a sodium ion $(+23.0)$, both showing an $\mathrm{m} / \mathrm{z}$ interval of 255, the molecular mass of a repeating unit. The peaks ionized by a proton satisfy the following formula: $2.0+35.5+58.1+(58.1+197.2) \times \mathrm{n}$ and $2.0+35.5+(58.1+197.2) \times \mathrm{n}$, where 2.0, 35.5, 58.1 and 197.2 are the molar masses of two protons, chloride, $\mathrm{PO}$ and TSI, respectively. The other population ionized by sodium corresponds to the formula: $23.0+35.5+1.0+58.1+(58.1+197.2) \times n$. All three populations confirmed the alternating nature of poly $(N$-tosyl propylene urethane) initiated by a chloride ion and terminated either by TSI or by $\mathrm{PO}$. 
It should be emphasized that the presence of both TBACl and TEB is indispensable for the copolymerization to occur. No reaction occurred at all in the absence of TBACl (Entry 5). On the other hand, in the absence of TEB, the copolymerization of TSI with $\mathrm{PO}$ proceeded slowly and resulted in a very low yield (34\%, Entry 6). Besides, the linear vs. cyclic selectivity decreased. The examination of the FTIR spectrum of the crude product (Figure S1) indicates in addition to the peak at $1736 \mathrm{~cm}^{-1}$, the presence of another peak at $1783 \mathrm{~cm}^{-1}$ characteristic of the cyclic oxazolidinone which is found to represent about $8 \%$ of the sample. Further characterization of the product of precipitation (Figure S2) shows an absorption at $1632 \mathrm{~cm}^{-1}$ that is attributable to the $\mathrm{C}=\mathrm{N}$ stretching, ${ }^{[23]}$ likely due to the tautomerization of urethane anion during chain propagation resulting in the formation of imidocarbonate linkages. Such a structure was also found in NMR characterization spectra. Multiple peaks appeared between 4.10 ppm and $4.80 \mathrm{ppm}$ in the ${ }^{1} \mathrm{H}$ NMR spectrum (Figure S3) instead of the two peaks at 3.91 and $4.94 \mathrm{ppm}$ for regular poly(propylene urethane); in comparison to the copolymer of Entry 3 , the peak at $148.8 \mathrm{ppm}$ corresponding to $\mathrm{C}=\mathrm{N}$ in ${ }^{13} \mathrm{C}$ NMR spectrum (Figure S4) also confirms the existence imidocarbonate linkages. The regiospecific formation of imidodithiocarbonate linkages was reported earlier for the copolymerization of isothiocyanate with thiirane, initiated by butyllithium. ${ }^{[24]}$ The regioselectivity leading to urethane linkages can be estimated from the ${ }^{1} \mathrm{H}$ NMR spectrum: urethane selectivity $(\%)=2 \times I_{5.05} \mathrm{ppm} / \mathrm{I}_{7.68 \mathrm{ppm}}$, where $I_{5.05 \mathrm{ppm}}$ and $\mathrm{I}_{7.68}$ ppm represent the integral area of the peak at $5.05 \mathrm{ppm}$ (methine adjacent to urethane) and $7.68 \mathrm{ppm}$ (phenyl), respectively. The value found is equal to $51 \%$; this indicates no regioselectivity in the absence of TEB. As can be seen, the addition of TEB activates $\mathrm{PO}$ and favor its addition to the urethane anion before the latter undergoes tautomerization. The reaction pathways leading to the formation of urethane and imidocarbonate linkages are shown in the supporting Scheme $2 b$.

Aiming at high molar mass samples, we then targeted a DP of 500 at $25^{\circ} \mathrm{C}$ (Entry 7). Although an exclusively linear polymer was obtained with a yield of $31 \%$, the urethane vs. imidocarbonate selectivity was only $73 \%$, a consequence of low activation of $\mathrm{PO}$ by TEB. Performing the same reaction at $60{ }^{\circ} \mathrm{C}$ resulted in a slightly lower linear vs. cyclic selectivity of $94 \%$ and a higher urethane vs. imidocarbonate selectivity of $80 \%$ with a significantly higher yield of $95 \%$; the molar mass of the copolymer synthesized was found equal to $104 \mathrm{~kg} / \mathrm{mol}$ (Entry 8). The urethane content could also be significantly increased by increasing the amount of TEB. Under otherwise same conditions, 4 equivalent of TEB gave $90 \%$ of urethane vs. imidocarbonate selectivity at room temperature (Entry 9).

Using a bulkier cation PPNCl as an initiator rather than TBACl afforded exclusively linear copolymers with a urethane vs. imidocarbonate selectivity in the range of $99 \%$; however, $5 \mathrm{~mol} \%$ of ether linkage were found by the ${ }^{1} \mathrm{H}$ NMR spectroscopy (Entry 10 , Figure S5). Increasing the molar ratio of TSI to PO to 1.5 suppressed the ether formation and afforded fully alternating polyurethane (Entry 11). This means that the copolymerization system allows to synthesize samples with varying contents in ether and urethane linkages. For example, copolymerizing TSI with $\mathrm{PO}$ at a feeding ratio of $1000 / 260$ in the presence of PPNCI and TEB gave a polymer with $70 \%$ of ether linkage and $30 \%$ of urethane linkage (Entry 20). Difunctional polyurethane could also be obtained when using a difunctional initiator $\mathrm{DHMB} / \mathrm{P}_{4}-t-\mathrm{Bu}$. Narrowly distributed polyurethane of $83 \mathrm{~kg} / \mathrm{mol}$ was obtained with a linear vs. cyclic selectivity of $99 \%$ and urethane vs. imidocarbonate selectivity of $92 \%$ (Entry 12 ).

Then the influence of the Lewis acidity of borane compounds on the rate of copolymerization was investigated. When triphenylborane (TPB), a stronger Lewis acid than TEB, is used to copolymerize TSI and PO in the presence of TBACI with a target DP of 100 , the polymerization proceeded explosively and released a large amount of heat. The linear vs. cyclic and urethane vs. imidocarbonate selectivity were both over $99 \%$ (Entry 13). It is noteworthy that a turnover frequency (TOF) of over $10000 \mathrm{~h}^{-1}$ was observed when carrying out the PO/TSI copolymerization with a low amount of TPB ( 0.5 equivalent to the initiator) - and a targeted DP of 1000 and PPNCl as initiator; nearly full conversion of $\mathrm{PO}$ was accomplished in 10 minutes (Entry 14). This reaction gave the highest molar mass of 225 $\mathrm{kg} / \mathrm{mol}$ and exclusively alternating polyurethane structure. On the contrary, tri-sec-butylborane, which is a weaker Lewis acid than TEB, had little effect on the PO/TSI copolymerization, which resulted in a low linear and urethane selectivity as well as a low yield (Entry 15).

The applicability of copolymerization of TSI with other epoxides was examined at room temperature under the following condition for the TSI/epoxide/TEB/I system: 110/100/2/1. The copolymerization of TSI with ethylene oxide (EO) was very fast and highly exothermic, neither oxazolidinone nor imidocarbonate were formed (Entry 16). The resulting poly( $N$-tosyl ethylene urethane) is not soluble in common organic solvent. In the case of 1-octene oxide $(\mathrm{OO})$, with a long alkyl group, polyurethane was obtained with $92 \%$ of urethane vs. imidocarbonate regioselectivity (Entry 17). Allyl glycidyl ether (AGE), a functionalized epoxide, was also successfully copolymerized with TSI affording exclusively alternating polyurethane in $99 \%$ yield (Entry 18$)$. In the case of cyclohexene oxide $(\mathrm{CHO})$ only $21 \%$ of urethane linkages were detected in the produced polymer (Entry 19). This low urethane vs. imidocarbonate selectivity and low yield are likely due to the high steric hindrance around $\mathrm{CHO}$, which preferred to be attacked by the non-substituted imidocarbonate oxygen anion rather than by the urethane nitrogen anion substituted by the tosyl group (Scheme 2B). The characterizations (FTIR, NMR, and SEC) of these polymers were shown in the supporting information (Figure S6-S15).

Based on the above observations, the mechanism of the TABmediated copolymerization of TSI and PO could be understood. As demonstrated by in-situ FTIR study of a model copolymerization of TSI and PO, the initiation process involves first the attack of the less hindered carbon of TEB-activated PO by the ate complex formed between the initiator, the chloride anion, and TAB; as shown in Figure 1E the carbonyl peak is seen only in a second step upon attack of TSI by the formed alkoxide anion, indicating that no reaction would occur in absence of $\mathrm{PO}$ and that TSI would then be inert. After addition of TSI, a tautomerization between urethane anions and imidocarbonate anions may occur (Scheme 2B) although the urethane nitrogen anion is considered more stable and thus thermodynamically more stable than the imidocarbonate anion due to the presence of electro-withdrawing tosyl group. This is the reason why increasing the temperature results in an increase of the urethane vs. imidocarbonate selectivity (entry 8 ). TEB can significantly lower the activation energy required for urethane formation; therefore increasing the amount of TEB (entry 9) or selecting TPB with a stronger Lewis acidity (entry 13,14 ) can favor the formation 
of urethane linkages. On the other hand, the formation of imidocarbonate requires a lower activation energy barrier, the active species formed being less hindered than in the case of urethane growing anions. In the case of $\mathrm{CHO}$, the monomer steric hindrance prohibits the formation of urethane anions and therefore more imidocarbonate linkages are formed as a kinetic product. In addition TEB-based ate complexes prevent undesired back-biting reactions, leading to the formation of oxazolidinone. The alternating structure of the polyurethane formed is thus the result of the higher reactivity of TSI than $\mathrm{PO}$ toward $\mathrm{RO}^{-}$while consecutive TSI propagation steps are prevented. Therefore, neither allophanate nor isocyanurate is present in the resulting sample. However, ether linkage may also form when the concentration of $\mathrm{PO}$ is relatively high.

The thermal degradation and glass transition temperature of poly ( $N$-tosyl propylene urethane) (Entry 3 ) were analyzed by TGA and DSC. The onset of the thermal degradation $\left(T_{\mathrm{d} \text { onset }}\right)$ and the glass transition temperature $\left(T_{\mathrm{g}}\right)$ were found to be $242^{\circ} \mathrm{C}$ and 107 ${ }^{\circ} \mathrm{C}$, respectively (Figure $\left.\mathrm{S} 16, \mathrm{~S} 17\right)$. The thermal stability is almost the same as that of poly (propylene carbonate) $\left(T_{\mathrm{d} \text { onset }} \approx 240{ }^{\circ} \mathrm{C}\right.$ ), while the $T_{\mathrm{g}}$ significantly increases because of urethane linkages in comparison with poly (propylene carbonate) $\left(T_{g}=22-40{ }^{\circ} \mathrm{C}\right) .{ }^{[25]}$ In comparison, the copolymer of $\mathrm{PO}$ and TSI with $51 \%$ of urethane selectivity (Entry 6) shows a $T_{\mathrm{d}}$ onset of $206{ }^{\circ} \mathrm{C}$ and a $T_{\mathrm{g}}$ of $94{ }^{\circ} \mathrm{C}$ (Figure S18, S19). Poly( $N$-tosyl octene urethane) (Entry 17) and poly (N-tosyl ally glycidyl ether urethane) (Entry 18) exhibit the same $T_{\mathrm{g}}$ of $55^{\circ} \mathrm{C}$ (Figure S20, S21). The values for poly(octene carbonate) and poly(ally glycidyl ether carbonate) are $-24{ }^{\circ} \mathrm{C}$ and $-12^{\circ} \mathrm{C}$, respectively. ${ }^{[26]}$ Interestingly, a melting peak is found at 61 ${ }^{\circ} \mathrm{C}$ upon heating and a crystallization peak can be seen at $44{ }^{\circ} \mathrm{C}$ upon cooling for poly( $N$-tosyl ethylene urethane) (Entry 16), implying a polymer of semi-crystalline nature (Figure S22). In conclusion, another heteroallene monomer, here TSI, could be anionically copolymerized with epoxides in the presence of trialkylborane and under metal-free conditions. The advantage of the described initiating system is that it requires only commercially available compounds and no synthesis of complex ligands associated with transition metals. Polyurethanes are obtained in this way with high selectivity without the formation of trimer cyclic isocyanurate when isocyanates with strong electro-withdrawing group are chosen. The success of this work paves the way to the copolymerization of epoxides with other heteroallene monomers and expands the range of polymerizations mediated by alkylboranes. Taking into account the better thermal properties of the polyurethane produced, the reported method provides access to the modification of properties of other polymers, especially aliphatic polycarbonates generated under the same conditions.

\section{Acknowledgements}

This research work is supported by KAUST under baseline funding (BAS/1/1374-01-01).

\section{Conflict of interest}

The authors declare no conflict of interest.

Keywords: $p$-tosyl isocyanate $\cdot$ epoxides $•$ trialkylborane $•$ anionic copolymerization $\bullet$ polyurethane
[1] H. W. Engels, H. G. Pirkl, R. Albers, R. W. Albach, J. Krause, A Hoffmann, H. Casselmann, J. Dormish, Angew. Chem. Int. Ed. 2013, 52, 9422-9441.

[2] a) C. S. Marvel, J. H. Johnson, J. Am. Chem. Soc. 1950, 72, 1674-1677; b) R. L. McKiernan, S. P. Gido, J. Penelle, Polymer 2002, 43, 3007-3017; c) A. S. More, T. Lebarbé, L. Maisonneuve, B. Gadenne, C. Alfos, H. Cramail, Eur. Polym. J. 2013, 49, 823-833; d) M. D. Zenner, Y. Xia, J. S. Chen, M. R. Kessler, ChemSusChem 2013, 6, 1182-1185.

[3] a) C. Hahn, H. Keul, M. Möller, Polym. Int. 2012, 61, 1048-1060; b) L. Maisonneuve, O. Lamarzelle, E. Rix, E. Grau, H. Cramail, Chem. Rev. 2015, 115, 12407-12439.

[4] a) S. Neffgen, H. Keul, H. Höcker, Macromolecules 1997, 30, 1289-1297; b) J. Kušan, H. Keul, H. Höcker, Macromolecules 2001, 34, 389-395.

[5] H. K. Hall, A. K. Schneider, J. Am. Chem. Soc. 1958, 80, 6409-6412.

[6] a) O. Haba, Y. Akashika, J. Polym. Sci. Part A: Polym. Chem. 2019, 57, 2491-2497; b) D. Zhang, Y. Zhang, Y. Fan, M. N. Rager, V. Guérineau, L. Bouteiller, M. H. Li, C. M. Thomas, Macromolecules 2019, 52, 27192724.

[7] a) O. Ihata, Y. Kayaki, T. Ikariya, Angew. Chem. Int. Ed. 2004, 43, 717719; b) O. Ihata, Y. Kayaki, T. Ikariya, Macromolecules 2005, 38, 6429 6434 .

[8] Z. Chen, N. Hadjichristidis, X. Feng, Y. Gnanou, Macromolecules 2017 , 50, 2320-2328.

[9] D. Zhang, S. K. Boopathi, N. Hadjichristidis, Y. Gnanou, X. Feng, J. Am. Chem. Soc. 2016, 138, 11117-11120.

[10] a) N. G. Patil, S. K. Boopathi, P. Alagi, N. Hadjichristidis, Y. Gnanou, X. Feng, Macromolecules 2019, 52, 2431-2438; b) M. Jia, N. Hadjichristidis, Y. Gnanou, X. Feng, ACS Macro. Lett. 2019, 8, 1594-1598.

[11] a) K. A. Andrea, F. M. Kerton, ACS Catal. 2019, 9, 1799-1809; b) Z. Chen, J. L. Yang, X. Y. Lu, L. F. Hu, X. H. Cao, G. P. Wu, X. H. Zhang, Polym. Chem. 2019, 10, 3621-3628.

[12] a) L. F. Hu, C. J. Zhang, H. L. Wu, J. L. Yang, B. Liu, H. Y. Duan, X. H. Zhang, Macromolecules 2018, 51, 3126-3134; b) H. Y. Ji, X. L. Chen, B. Wang, L. Pan, Y. S. Li, Green Chem. 2018, 20, 3963-3973; c) A Kummari, S. Pappuru, D. Chakraborty, Polym. Chem. 2018, 9, 4052 4062.

[13] J. L. Yang, H. L. Wu, Y. Li, X. H. Zhang, D. J. Darensbourg, Angew. Chem. Int. Ed. 2017, 56, 5774-5779.

[14] a) Y. Chen, J. Shen, S. Liu, J. Zhao, Y. Wang, G. Zhang, Macromolecules 2018, 51, 8286-8297; b) C. J. Zhang, H. Y. Duan, L. F. Hu, C. H. Zhang, X. H. Zhang, ChemSusChem 2018, 11, 4209-4213.

[15] a) J. Min, P. N. Shah, J. H. Ahn, J. S. Lee, Macromolecules 2011, 44, 3211-3216; b) J. S. Lee, S. W. Ryu, Macromolecules 1999, 32, 20852087; c) Y. Nambu, T. Endo, J. Org. Chem. 1993, 58, 1932-1934; d) H. A. Duong, M. J. Cross, J. Louie, Org. Lett. 2004, 6, 4679-4681.

[16] Y. Toda, S. Gomyou, S. Tanaka, Y. Komiyama, A. Kikuchi, H. Suga, Org. Lett. 2017, 19, 5786-5789.

[17] M. Jurrat, B. J. Pointer-Gleadhill, L. T. Ball, A. Chapman, L. Adriaenssens, J. Am. Chem. Soc. 2020, 142, 8136-8141

[18] Z. Li, R. J. Mayer, A. R. Ofial, H. Mayr, J. Am. Chem. Soc. 2020, 142, 8383-8402.

[19] R. J. P. Corriu, G. F. Lanneau, V. D. Mehta, Heteroat. Chem. 1991, 2 , 461-463.

[20] Z. Shen, X. Lu, A. Lei, Tetrahedron 2006, 62, 9237-9246.

[21] P. ten Holte, Bart C. J. van Esseveldt, L. Thijs, B. Zwanenburg, Eur. J. Org. Chem. 2001, 2001, 2965-2969.

[22] L. C. Du, Y. Z. Meng, S. J. Wang, S. C. Tjong, J. Appl. Polym. Sci. 2004 92, 1840-1846.

[23] J. D. Larsen, H. Bundgaard, Int. J. Pharm. 1989, 51, $27-38$.

[24] G. Belonovskaya, Z. Tchernova, B. Dolgoplosk, Eur. Polym. J. 1972, 8, 35-52.

[25] S. D. Thorat, P. J. Phillips, V. Semenov, A. Gakh, J. Appl. Polym. Sci. 2003, 89, 1163-1176.

[26] M. Jia, D. Zhang, G. W. de Kort, C. H. R. M. Wilsens, S. Rastogi, N. Hadjichristidis, Y. Gnanou, X. Feng, Macromolecules 2020, 53, 52975307. 


\section{Entry for the Table of Contents}

\section{Polyurethanes from Direct Organocatalytic Copolymerization of $p$-Tosyl Isocyanate with Epoxides}

Mingchen Jia, Nikos Hadjichristidis, Yves Gnanou, ${ }^{*}$ and Xiaoshuang Feng*

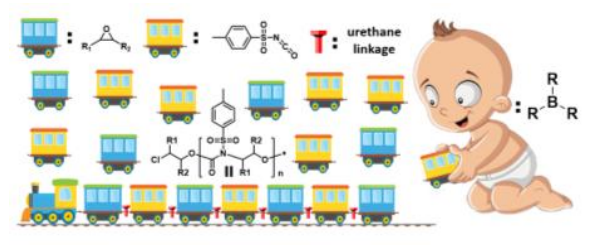

The direct copolymerization of epoxides with p-tosyl isocyanate was achieved in the presence of trialkylborane, and polyurethanes could be obtained without the formation of cyclic isocyanurate in high linear/cyclic and urethane/imidocarbonate selectivity. The reported method provides access to the modification of properties of other polymers, especially aliphatic polycarbonates generated under the same conditions.

Keywords: $p$-tosyl isocyanate $\cdot$ epoxides $\cdot$ trialkylborane $\cdot$ anionic copolymerization $\cdot$ polyurethane 